\title{
Variations in the Blood Supply of Kidneys: Cadaveric and Autopsy Findings
}

\author{
Authors \\ Dr Rachna Agrawal ${ }^{1}$, Dr Manish Kumar Singhal*2 \\ ${ }^{1}$ Senior Demonstrator, Dept of Anatomy, Medical College, Bharatpur, Rajasthan, India \\ ${ }^{2}$ Assistant Professor, Dept of Pathology, SMS Medical College, Jaipur, India \\ Corresponding Author \\ Dr Manish Kumar Singhal \\ Assistant Professor Department of Pathology, SMS Medical College Jaipur, India
}

\begin{abstract}
Introduction: Renal arteries originates at right angle from the abdominal aorta just below the superior mesenteric artery at the level of intervertebral disc between L1 and L2 vertebra and take about $20 \%$ of the cardiac output. The venous drainage occurs through the paired renal veins which drain into the inferior vena cava. Both these vessels enter through the hilum of the kidney. Variations in blood supply of kidney are so frequent. Hence, this study would serve a useful guideline for performing uroradiological procedures and renal transplant surgeries and for treating renal trauma and hydronephrosis.

Materials and Methods: Present study conducted on 30 formalin fixed human cadavers used for routine abdominal dissection for undergraduate students and 15 autopsy specimens. The kidneys were examined and blood supply and its variations were noted.

Results: The following anatomical findings are observed in this study: (i) Superior polar arteries (ii) Inferior polar artey (iii) Extra hilar artery (iv) Accessory renal artery (v) Accessory renal vein and (vi) Hilar relations of renal vessels and pelvis

Conclusion: So knowledge of the normal anatomy and variational pattern in the blood supply of kidney is more important for the surgeons, radiologists and urologists to perform any angiographic studies for renal transplantation, interventional radiologic procedures and urologic operations.

Keywords: Renal artery, Renal vein, Variation, Accessory renal arteries, Superior polar arteries, Inferior polar arteries, Segmental arteries.
\end{abstract}

\section{Introduction}

Renal arteries originates at right angle from the abdominal aorta just below the superior mesenteric artery at the level of intervertebral disc between L1 and L2 vertebra but very rarely the main renal artery originates from superior mesenteric artery, coeliac trunk, common iliac artery, external iliac artery, gonadial artery. ${ }^{[1]}$ These are end arteries with no anastomoses. Abdominal aorta lies on the left side of the vertebral column, therefore the right renal artery is longer than the left renal artery. ${ }^{[2]}$

The venous drainage occurs through the paired renal veins which drain into the inferior vena cava. Both these vessels enter through the hilum of the kidney. The renal arteries take about $20 \%$ of the cardiac output. ${ }^{[3]}$ Every minute about $1200 \mathrm{ml}$ of blood passes through the kidneys.

Blood supply to kidney is characterised by the presence of variations, both in renal artery and 
renal vein. Significance in the variations of the origin of the renal artery has gained importance with the advent of renal transplant and conservative renal surgeries.

Extra renal artery if present usually originates from abdominal aorta. It may enter the kidney either through the hilum or through the surface of kidney. They may enter either through upper pole or lower pole as polar arteries or near hilum as extra hilar artery ${ }^{[4]}$. The hilum limits were set by a line drawn between the two most medial points in the frontal plane of each kidney.

The nomenclature adapted by Sampaio and Passos in 1992 was: hilar artery- branch of aorta that penetrates the kidney in hilum; extra-hilar arterybranch of renal artery that presents an extra hilar penetration (in superior or inferior poles); superior polar artery- branch of aorta penetrates the kidney at the superior pole; inferior polar artey- branch of aorta that penetrates the kidney at the inferior pole.

So knowledge of the anatomy and variational pattern in the blood supply of kidney is more important for renal transplantation, interventional radiologic procedures and urologic operations.

Hence, this study would serve a useful guideline for performing uroradiological procedures and renal transplant surgeries and for treating renal trauma and hydronephrosis.
30 kidney specimen from routine autopsy(15) received in pathology department and 60 kidneys [30 cadavers] from routine abdominal dissection conducted for medical undergraduates irrespective of sex, aged 40-70 years from Department of Anatomy, SMS Medical College, Jaipur, Rajasthan were taken. So total 90 kidney specimen [45 right kidney and 45 left kidney] were examined for morphological variations of blood supply of kidney. Various organs including stomach, liver, spleen, duodenum with pancreas were removed and preserved as specimen for teaching purposes. In some cases Ureters and renal vein also reflected for proper visualization of hilar pattern of renal artery. The renal arteries were observed according to their number (sum of renal arteries originating from the aorta) and early segmental and extra hilar branches of the main renal artery on each kidney.

\section{Results}

Among the 90 kidneys which were dissected from 30 preserved cadavers and 15 autopsy specimen, the normal pattern of blood supply to the kidneys was observed in $67.77 \%$ cases. The following variations were observed in the remaining $32.23 \%$ cases

\section{Material and methods}

Table 1: Incidence of variations in branching pattern of renal vessels

\begin{tabular}{|l|l|l|l|l|}
\hline $\begin{array}{l}\text { Sl. } \\
\text { No. }\end{array}$ & Type of variation & $\begin{array}{l}\text { Right side } \\
(\text { no\&\%) }\end{array}$ & $\begin{array}{l}\text { Leftt side } \\
(\text { no\&\%) }\end{array}$ & $\begin{array}{l}\text { Total } \\
(\text { no\&\%) }\end{array}$ \\
\hline 1 & Superior polar artey & $8(8.88 \%)$ & $6(6.66 \%)$ & $14(15.55 \%)$ \\
\hline 2 & Inferior polar artey & $2(2.22 \%)$ & $0(0 \%)$ & $2(2.22 \%)$ \\
\hline 3 & Both Superior and Inferior polar artey in same kidney & $1(1.11 \%)$ & $0(0 \%)$ & $1(1.11 \%)$ \\
\hline 4 & Extra hilar artery & $3(3.33 \%)$ & $1(1.11 \%)$ & $4(4.44 \%)$ \\
\hline 5 & Accessory renal artery & $2(2.22 \%)$ & $1(1.11 \%)$ & $3(3.33 \%)$ \\
\hline 6 & Accessory renal vein & $4(4.44 \%)$ & $1(1.11 \%)$ & $5(5.55 \%)$ \\
\hline
\end{tabular}

Table 2: Incidence of variations in Hilar relations of renal vessels and pelvis (from anterior to posterior)

\begin{tabular}{|l|c|c|c|c|}
\hline Sl. No. & Renal Hilar relation & $\begin{array}{c}\text { Right side } \\
(\mathbf{n o} \text { \& \%) }\end{array}$ & $\begin{array}{c}\text { Left side } \\
(\mathbf{n o} \& \%)\end{array}$ & $\begin{array}{c}\text { Total } \\
(\text { no \& \%) }\end{array}$ \\
\hline 1 & VAP & $36(40 \%)$ & $40(40.44 \%)$ & $76(84.44 \%)$ \\
\hline 2 & AVP & $7(7.77 \%)$ & $5(5.55 \%)$ & $12(13.33 \%)$ \\
\hline 3 & PAV & $2(2.22 \%)$ & $0(0 \%)$ & $2(2.22 \%)$ \\
\hline
\end{tabular}

VAP(Vein, Artery, Pelvis), AVP(Artery, Vein, Pelvis), PAV(Pelvis ,Artery, Vein) 
Fig:1 Right kidney showing superior polar artery(Cadaveric and autopsy finding)

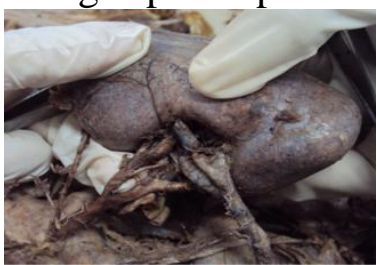

(a)

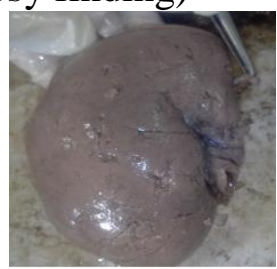

(b)

Fig:2 Right kidney showing Inferior polar artery(Cadaveric finding)

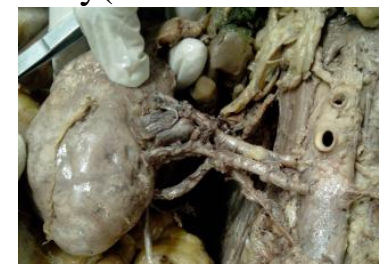

Fig:3 Right kidney showing Superior and Inferior polar artery (Autopsy finding)

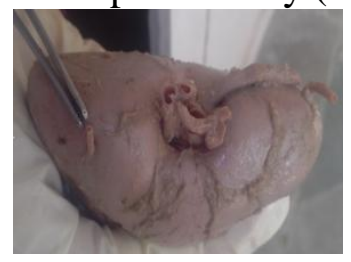

Fig:4 Right kidney showing extra hilar artery(a)\&(b) and superior polar artery in (b)(Cadaveric finding)

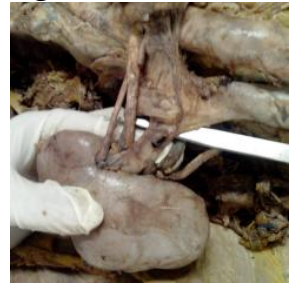

(a)

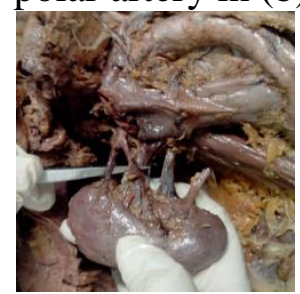

(b)

Fig:5 Right kidney showing accessory renal artery (Cadaveric finding)

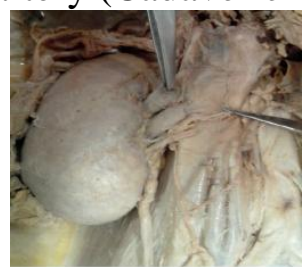

Fig:6 Left kidney showing Accessory renal vein (Cadaveric finding)

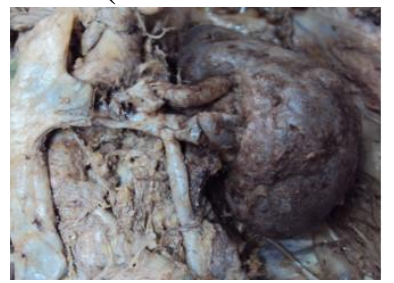

Fig:7 Picture showing Accessory renal vein in right kidney(a) and multiple tributaries of left renal vein (a),(b) (Cadaveric finding)

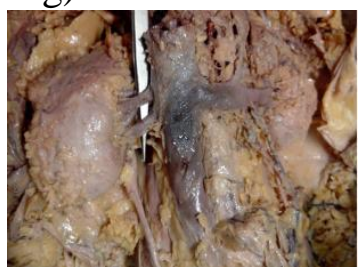

(a)

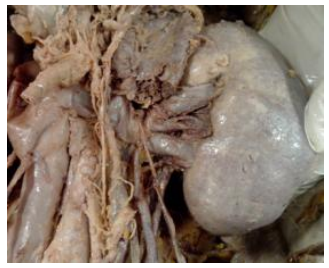

(b) 


\section{Discussion}

Variations in renal arteries accounts for about $30 \%$ of its existence ${ }^{[1]}$. These variations are classified as accessory or aberrant renal arteries. Accessory renal arteries are additional arteries which pass along with normal renal arteries through the hilum. In which hilar artery is branch of aorta that penetrates the kidney in hilum; extrahilar artery is branch of renal artery that presents an extra hilar penetration (in superior or inferior poles). Aberrant arteries are those which enter the kidney by piercing the substance of the kidney, either through upper pole or lower pole as polar arteries. superior polar artery- branch of aorta penetrates the kidney at the superior pole; inferior polar artey- branch of aorta that penetrates the kidney at the inferior pole. ${ }^{[5]}$

All these variations can be explained on embryological basis. Renal, suprarenal and gonadal organs are supplied by dorsal aorta, by lateral mesonephric arteries. ${ }^{[6]}$ According to Felix, these lateral mesonephric arteries are divided into upper, middle and lower groups. The middle group, namely $6-9^{\text {th }}$ segment, gives rise to renal arteries. Persistence of more than one renal artery in the middle group results in accessory renal $\operatorname{arteries}^{[7]}$.

The various types of pre-hilar branching patterns which were observed were fork, duplicate, triplicate and ladder patterns. These multiple branches represent the segmental distribution of the kidney ${ }^{[8]}$ and so, the risk of a haemorrhage during transplantation, segmental ischaemia and post operative haemorrhage are more.

Saldarriage et al., observed bilateral additional artery in $7.7 \%$ cases, $12 \%$ arteries entered through the hilum and $1.8 \%$ cases inferior polar arteries ${ }^{[9]}$. In present study, we reported bilateral additional renal arteries and both inferior and superior polar arteries.

Bordei $\mathrm{P}$ et al., in their renal vasculature, studied 54 cases, out of which arteries were entered through hilum in 24 cases, 16 were inferior polar arteries were in 16 cases and superior polar arteries in 5 cases $^{[10]}$. In present study, both the additional and aberrant arteries arose from the abdominal aorta.

Anupama et al., studied 30 cadavers and reported right side supernumerary renal vein in 10 cases and bilateral renal vein variation in only one case [11]

Renal arterial variations are more frequently observed than renal veins, which account for about $18 \%$ of the cases.

Variations in renal veins are caused by anomalies which are related to the development of inferior vena cava ${ }^{[12]}$. The literature has described renal vein variations which were more common on the right side $(28 \%)$ than on the left side $(1 \%)^{[13]}$. In present study, we also reported supernumerary renal veins.

\section{Conclusion}

The accessory or aberrant renal arteries important for the clinicians, they have a vital role to play in causation of hydronephrosis, renal transplantations and in micro vascular surgeries. Variations in renal veins are commonly discovered during venography or any operative procedures.

Knowledge of the anatomy and variational pattern in the blood supply of kidney is more important for renal transplantation, interventional radiologic procedures and urologic operations. So, present study would be helpful to guide for performing uroradiological procedures and renal transplant surgeries and for treating renal trauma and hydronephrosis.

\section{References}

1. Snell R.S. Clinical anatomy 7th ed. Philadelphia; USA: Lippincott Williams \& Wilkins.2004.p. 283

2. Sing Indirbir. Text book of anatomy vol 2, 5th ed. New Delhi; India: Jaypee Brothers; 2011.

3. Gary AT, Kevin TP. Anatomy \& physiology 2nd ed. USA:Mosby;1993.

4. Ramesh Rao T, Rachana. Aberrant renal arteries and its clinical significance: A 
case report. International Journal of Anatomical Variations. 2011; 4:37-39.

5. Sharmila Aristotle et al., Variations in the Blood Supply of Kidney ,Journal of Clinical and Diagnostic Research. 2013 Aug, Vol-7(8): 1555-1557 .

6. Virendra Budhiraja, Rakhi Rastogi, Asthana AK. Renal artery variations: embryological basis and surgical correlation. Romanian Journal of Morphology and Embryology. 2010; 51(3):533-36.

7. Felix WN. Manual of human embryology, Keibel and Mall. 1912; 2nd ed;833.

8. Bergman RA, Thompson SA, Afifi AK Saadeh F. A Compendium of human anatomical Variation. Baltimore: Urban and Schwarzenberg; 1988.

9. Saldarriage AF, Perez LE, Ballesteros. A direct anatomical study of additional renal arteries in a Colombian Mestizo population Folia Morphol. 2008;67:129-34.

10. Bordei P, Saote E, Iliescu D. Double renal arteries originating from the aorta. Surg. Radiol. Anat. 2004;26:474-79.

11. Anupma Gupta, Raman Gupta, Rikki Singal. Congenital variations of renal veins: Embryological background and clinical implications. Journal of Clinical and Diagnostic Research. 2011; 6:114043.

12. Favaro WJ, Santos TD, Cagnon VHA. Venous communication between right and left kidneys. A rare anatomical variation. case report. Int. J. Morphol. 2009; 27(1):117-20.

13. Testut L Laterjet A, tratado de anatomia Humana..Barcelona, salvat. 8th ed;1947; 4. 